\title{
Expression of CD15 antigen in urinary bladder transitional cell carcinoma
}

\author{
D M Parham, K Morton, G Coghill, A J Robertson, M A Kerr
}

\begin{abstract}
The biopsy specimens of 91 patients between the ages of 38 and 94 with transitional cell carcinoma of the bladder were retrospectively reviewed to determine if the expression of CD15 antigen detected by a monoclonal antibody MC2 was correlated with prognosis. Expression was variable, ranging from strong expression of the antigen by only the superficial cells in well differentiated papillary lesions to weak expression by most cells in solid or invasive tumours. In the invasive component there was a correlation between MC2 expression and tumour type, suggesting that the cell surface carbohydrate detected by MC2 may have a role in cell adhesion. There was no correlation between staining and survival.
\end{abstract}

It is concluded that tumour type, grade, and stage remain the best prognostic indicators of urothelial tumours.

The 3 fucosyl N-acetylactosamine (CD15) antigen is a carbohydrate residue that is recognised by a family of monoclonal antibodies raised independently of one another.' MC2 is one of these antibodies and has been developed in the Department of Pathology, University of Dundee. Studies in this department have shown previously that the antigen recognised by $\mathrm{MC} 2$ is present in a variety of embryonic and extra-embryonic tissues and is found on the outer cell membrane of a variety of epithelial and in intra- and extra-cellular mucins. ${ }^{23}$ Further studies have also shown that the pattern of expression in cervical squamous epithelium varies with the degree of cervical intraepithelial neoplasia (CIN) present. ${ }^{4}$ In normal bladder urothelium only the superficial layer of cells express this antigen, suggesting that the use of the monoclonal antibody $\mathrm{MC} 2$ could be an indicator of urothelial differentiation. Preliminary observations on transitional cell carcinomas of the bladder showed a changed pattern of expression in neoplasia. In an attempt to determine if this was of prognostic importance a retrospective study was carried out.

\section{Methods}

The original biopsy specimens were reviewed from 100 patients (age range 38-94) who had transitional cell carcinoma of the bladder, registered with the Cancer Registry in Dundee between 1975 and 1977. Of these, nine patients were excluded due to insufficient remaining material for examination or inadequate information on clinical follow up. Follow up for the purposes of this study stopped in July 1987. The original sections were reviewed by one pathologist (KM). Tumours were typed according to their architectural growth pattern-that is, papillary, mixed, or solid transitional cell carcinomas. Standard histological criteria were used to grade and stage the neoplasms. ${ }^{56}$ Further sections ( $5 \mu \mathrm{m}$ thick) were processed for immunohistochemical staining by the avidin-biotin technique using the method described previously. ${ }^{7}$ The expression of the CD15 antigen with MC2 was assessed for three different cell populations; $(a)$ the single layer of luminal superficial epithelial cells; (b) deep epithelial cells; and (c) invasive cells. In each of these three areas 100 cells were assessed and the percentage of the cells showing membrane staining was scored as follows: $0=$ no expression; $1=\leqslant 50 \%$ of cells showing positive membranous staining; 2 $=>50-\leqslant 80 \%$ of cells showing positive membranous staining; $3=>80 \%$ of cells showing positive membranous staining.

Statistical evaluation was carried out using the $\chi^{2}$ test and the logrank test.

\section{Results}

Figure 1a shows the staining by MC2 of the cell membranes of normal superficial urothelial cells. In the series of tumours examined urothelial staining with MC2 varied considerably, ranging from strong expression of the antigen by only the superficial cells in well differentiated papillary lesions to weak expression of the antigen by most cells in solid or invasive tumours (figs $1 \mathrm{~b}-\mathrm{d}$ ). Pretreatment of sections with neuraminidase did not affect the results. A summary of the findings is presented in the table.

Eighteen of the 34 grade I tumours (well differentiated) showed that $\mathrm{MC} 2$ was confined to the superficial cells or less than half of the deeper non-invasive cells. In the other 16 cases, however, there was uniform expression of varying degrees in both superficial and deep cell components.

Of the 34 grade II tumours (moderately well differentiated), ${ }^{10}$ in only four was expression of the antigen confined to the superficial cells. In the remainder, the antigen was also 


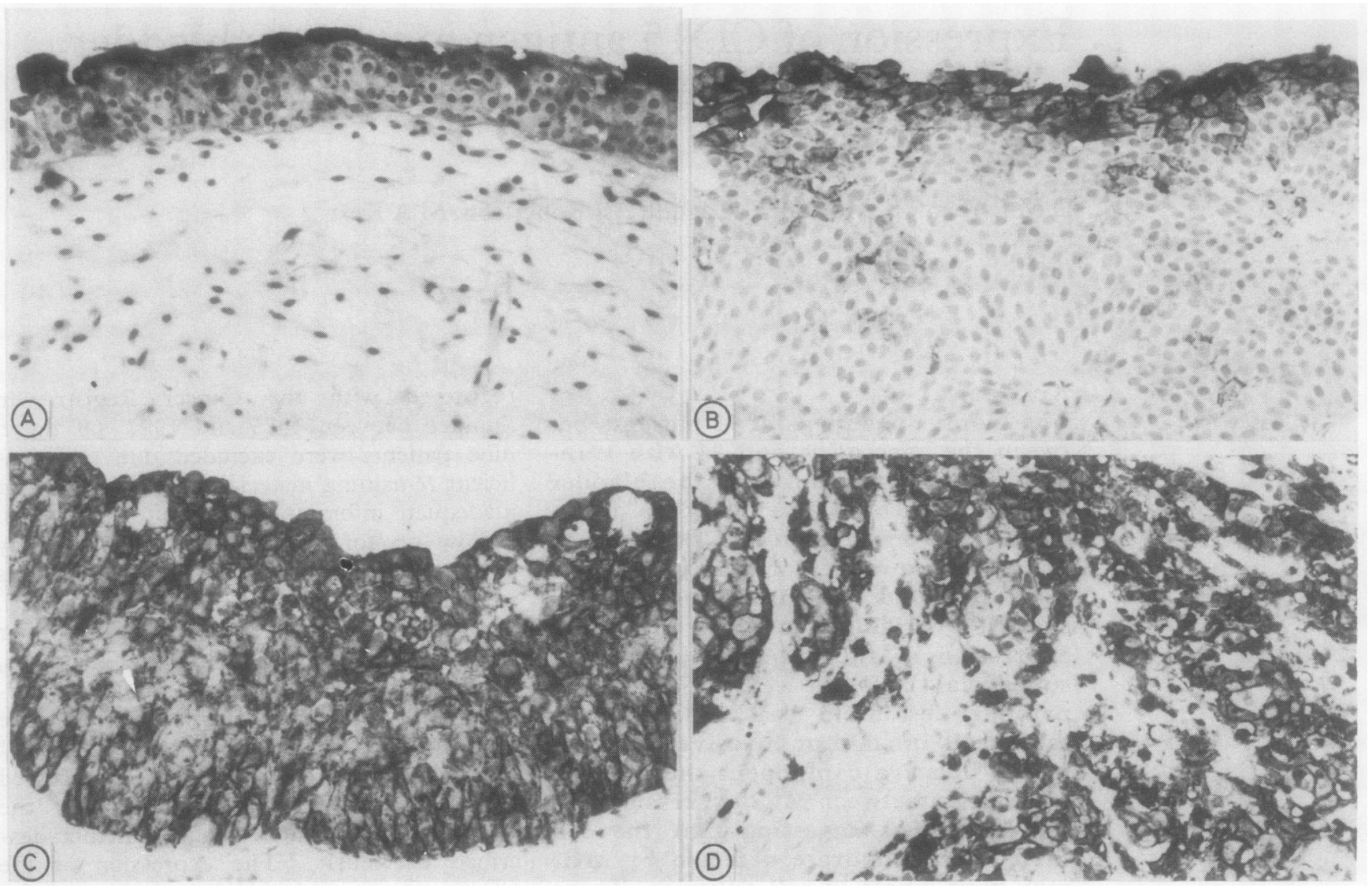

Examples of different staining observed with MC2. (A) Staining of normal urothelium; (B) staining confined to the superficial (luminal surface) cell layers in a transitional cell carcinoma; (C) staining of the superficial and deep cell layers in a transitional cell carcinoma; (D) staining of invasive tumour.

sed in the deeper and invasive components to varying degrees.

The 23 grade III (poorly differentiated) tumours showed considerable variability of expression. In 12, more than half the cells in the deep or intvasive components stained positively. Of the remainder, eight showed scanty expression in any of the compartments and the remaining three had a high score for superficial expression and a low score for deep expression, similar to that of well differentiated papillary tumours.

Thirty three tumours were thought to have been invasive on the results of the original histological examination, but immunohistochemical staining identified one additional case of early subepithelial invasion not previously recognised on sections stained with haematoxylin and eosin. The invasive component in 16 of these cases scored 3 for expression, another six cases scored 2 , and six cases scored 1 -in two thirds of the neoplasms more than half the invasive cells expressed the antigen. In six cases, however, there was no expression at all by the invasive cells: this included three high grade (poorly differentiated) tumours.

Expression of MC2 in different cell compartments

\begin{tabular}{lllll}
\hline Expression of $M C 2$ & Survival & Grade & Stage & Tumour type \\
\hline Area assessed & & & & \\
Superficial cells & $\mathrm{p}>0.9$ & $\mathrm{p}<0.80$ & $\mathrm{p}<0.78$ & $\mathrm{p}<0.10$ \\
Deep cells & $\mathrm{p}<0.25$ & $\mathrm{p}<0.70$ & $\mathrm{p}<0.74$ & $\mathrm{p}<0.04$ \\
Invasive cells & $\mathrm{p}<0.1$ & $\mathrm{p}>0.39$ & $\mathrm{p}<0.79$ & $\mathrm{p}<0.018$ \\
\hline
\end{tabular}

Statistical analysis of the results confirmed that the previously defined criteria (grade, stage, and tumour type) correlated well with survival (grade, $\mathrm{p}<<0.001$, stage, $\mathrm{p}<$ 0.001 , tumour type (papillary $/$ mixed/solid) $p$ $<<0.001$ ). Only one significant correlation was found with MC2 staining-expression in the invasive component was strongest in the predominantly papillary tumours and weakest in the solid tumours (table).

\section{Discussion}

It has recently been shown that expression of the high molecular weight epithelial membrane antigen recognised by the monoclonal antibody HMFG2 in transitional cell carcinomas is of prognostic value and may be a sensitive indicator of malignant transformation. ${ }^{8}$ Studies with MC2 have also shown differences in cell surface carbohydrate expression in malignant and premalignant epithelia. ${ }^{34}$ In a pilot study with MC2 it was suggested that there may be a correlation between staining and the histological grade and stage of the transitional cell carcinomas. Statistical analysis of the larger series of cases reported here has failed to show any consistent findings but shows a wide variation in staining between different neoplasms. Expression of MC2 was not related to prognosis even when staining was assessed in a similar manner to that used by Conn et al with HMFG 2. ${ }^{8}$ A good correlation, however, was observed between MC2 expression and histological growth pattern (tumour type) of the 
invasive tumour component, suggesting that the cell surface carbohydrate detected by MC2 may have a role in cell adhesion.

In normal mature cervical squamous epithelium the suprabasal cells stain with $\mathrm{MC} 2$ and expression of the CD15 antigen is thought to be a marker of cell differentiation, as the proportion of this zone of suprabasal cells expressing the antigen diminishes progressively with increasing severity of CIN. ${ }^{4}$ Furthermore, in cervical carcinomas changes in the glycocalyx, where the CD15 antigen is located, have been found on electron microscopical examination. ${ }^{9}$

In transitional cell carcinomas of the bladder the zone of expression seems to increase progressively with the development of malignancy, suggesting that at least in the bladder $\mathrm{CD} 15$ is not a marker of cell differentiation. The reason for this variable pattern of expression is unclear; it may be that in the bladder mucosa MC2 is directed against a secretory product which diffuses back into the mucosa as a result of changed adhesion associated with malignant transformation, or that changes in the glycocalyx associated with malignant transformation are similar to those occurring in the terminally differentiated superficial cells. If this second hypothesis is correct it may be more appropriate to examine urothelium peripheral to the cystoscopically visible tumour with MC2 as these are the sites of precancerous change which are presumably more likely to give rise to recurrent tumours.
Although this study did not show any significant correlation between the expression of the antigen recognised by $\mathrm{MC} 2$ in bladder tumours and prognosis, it has raised further questions about the biological role of 3 fucosyl$\mathrm{N}$-acetyllactosamine carbohydrate residues in malignancy.

1 Kerr MA, McCarthy NC. A carbohydrate differentiation antigen of granulocytes, brain and many tumours. Biochem Soc Trans 1985;13:424-6.

2 McCarthy NC, Simpson JRM, Coghill G, Kerr MA Expression in normal adult, fetal and neoplastic tissues of a carbohydrate differentiation antigen recognised by antigranulocytic mouse monoclonal antibodies. J Clin Pathol 1985;38:521-9.

3 Sanders DSA, Kerr MA, Hopwood D, Coghill G, Milne GA. Expression of the 3-fucosyl N-acetyllactosamine (CD15) antigen in normal, metaplastic, dysplastic and neoplastic squamous epithelia. J Pathol 1988;154:155-62.

4 Sanders DSA, Kerr MA, Hopwood D, Coghill G. Expression of the CD15 antigen is a marker of cellular differentiation in cervical intraepithelial neoplasia (CIN). J Pathol 1988;155:207-12.

5 UICC. In: Hermanek P, Sobin LH, eds. TNM classification of malignant tumours. 4th ed. Berlin: Springer-Verlag,

6 Mostofi FK, Sobin LH, Torloni H. Histological typing of urinary bladder tumours. In: International histological classification of tumours. No 10. Geneva: World Health Organisation, 1973.

7 Coggi G, Dell'Orto P, Viale G. Avidin-biotin methods. In: Polak JM, Van Noorden S, eds. Immunocytochemistry: modern methods and applications. Bristol: John Wright \& Sons Ltd, 1986:54-70.

8 Conn IG, Crocker J, Emtage LA, Wallace DMA. HMFG-2 as a prognostic indicator in superficial bladder cancer. as a prognostic indicator in Pathol 1988;41:1191-5.

9 Choncha M, Caorsi I, Rodriguez EM. Cytochemistry and ultrastructure of normal and neoplastic cells exfoliated from the human cervix. Ultrastruct Pathol 1986;10:23-38. 